Brit. J. industr. Med., 1955, 12, 92.

\title{
PULMONARY FIBROSIS IN NON-FERROUS FOUNDRY WORKERS
}

\author{
BY \\ H. E. HARDING and A. I. G. McLAUGHLIN \\ From the Department of Pathology, Sheffield University, and the Factory Department, \\ Ministry of Labour and National Service
}

(RECEIVED FOR PUBLICATION OCTOBER 15, 1954)

Much has been written about fume fever (brass caster's ague, zinc chills, zinc shakes), and lead poisoning in brass foundries has been dealt with recently by Stalker (1947) and Hamlin and Weber (1947), but the references to pulmonary fibrosis amongst non-ferrous foundry workers are few. Stalker wrote that "the incidence of advanced silicosis has been generally low among [brass] foundrymen ".

Many surveys of the incidence of pulmonary fibrosis in iron and steel foundry workers have been made, and some of them have also included groups of non-ferrous foundry workers. These include the reports by Trice and Easom (1936), Greenburg, Siegel, and Smith (1938), Sander (1939), Brown and Klein (1942), Riley, Butler, and Goren (1945) and Vigliani, Parmeggiani, and Zanetti (1948). The term " non-ferrous" includes alloys with a copper base (brass, bronze, and gunmetal) and also with an aluminium or a magnesium base. It is unusual to find specific references in these reports to brass foundries, and no pathological studies of brass founders' lungs have hitherto been reported.

Since 1936 only 10 deaths from silicosis (with or without tuberculosis) in brass workers have come to the notice of the Factory Department. But these " accidental" cases give no information about the real incidence of silicosis in this trade. Only careful surveys, which combine clinical, $x$-ray, environmental, and pathological studies, provide such information. There may well be a close analogy between the brass- and iron-founding industries. In the latter, it was thought for years that there was little risk of silicosis and other forms of pneumoconiosis, because few cases had come to the notice of either the Factory Department or the Silicosis Medical Board. When an extensive survey was made (McLaughlin and others, 1950) it was found that the incidence of silicosis and mixed-dust pneumoconiosis, particularly in moulders who made small castings, was moderately high, especially if siliceous parting powders had been used. It was also found that the dominant pathological lesion in these workers was the mixeddust pneumoconiosis nodule and not the classical silicotic nodule.

Again, the non-ferrous metals, including brass, are cast either in sand moulds or in metal moulds (die-casting). No siliceous dust is created when diecasting takes place. If therefore the results of surveys (usually by radiography alone) of nonferrous foundry workers are given, and no attempt made to separate the sand-casters from the diecasters, a false impression of the incidence of silicosis will be given.

In this article we present the pathological details of six non-ferrous (mainly brass) foundry workers (four moulders and casters and two fettlers) together with such clinical, radiological, and environmental details as were available. In five instances the casting of the various metals was done in sand moulds and in the sixth in iron moulds.

\section{Case Histories}

Case 1.-C. C. was aged 60 years when he died. $\mathrm{He}$ had been employed as a moulder and caster of non-ferrous metals (brass, bronze, aluminium) for 29 years up to 1942 when he became a charge-hand and thereafter did only a little moulding. In this foundry Mansfield red sand is used for making moulds. Accurate information about parting powders was difficult to obtain, but that used from 1920 until about 1940 was said to consist of ground fireclay bricks $(60 \%$ free silica) and furnace ashes. Since that time a parting powder with a total silica content of $0.3 \%$ has been used.

He began to have "chest trouble" two years before his death. He attended a chest clinic in May, 1945, where he was found to have pulmonary tuberculosis. Tubercle bacilli were found in his sputum on four occasions. An $x$-ray film of the chest taken at this time showed the presence of "fibroid tuberculosis" in both lungs. The report was "very marked fibrosis 
of the lungs. Large hazy patches extending from both roots into the upper lobes show marked calcification". The appearances also suggested the presence of silicosis, and inquiries about the man's occupation were made. He was admitted to hospital in August, 1945. Further $x$-ray examination was made in October, 1945, and the report was of " silicosis of the lungs with definite tuberculous infiltration in both mid-zones". He died in November, 1945, having last worked in July of the same year.

To the naked eye the lungs after fixation showed fibrous adhesions over most of both lungs and acute pleurisy over the basal areas where fibrosis was absent. The lungs were bulky with some emphysematous bullae : ragged cavities were present in the apical portion of each lobe of the left lung, and tuberculous bronchopneumonia was evident throughout both lungs. Also seen throughout both lungs were numerous small, hard, black areas most of which were intimately associated with tuberculosis, but a few in the lower parts appeared separate from the infectious process.

Microscopical examination showed tuberculosis of varying age, considerable silico-tuberculous nodulation (Fig. 1) and areas of fibrosis that appeared purely silicotic.

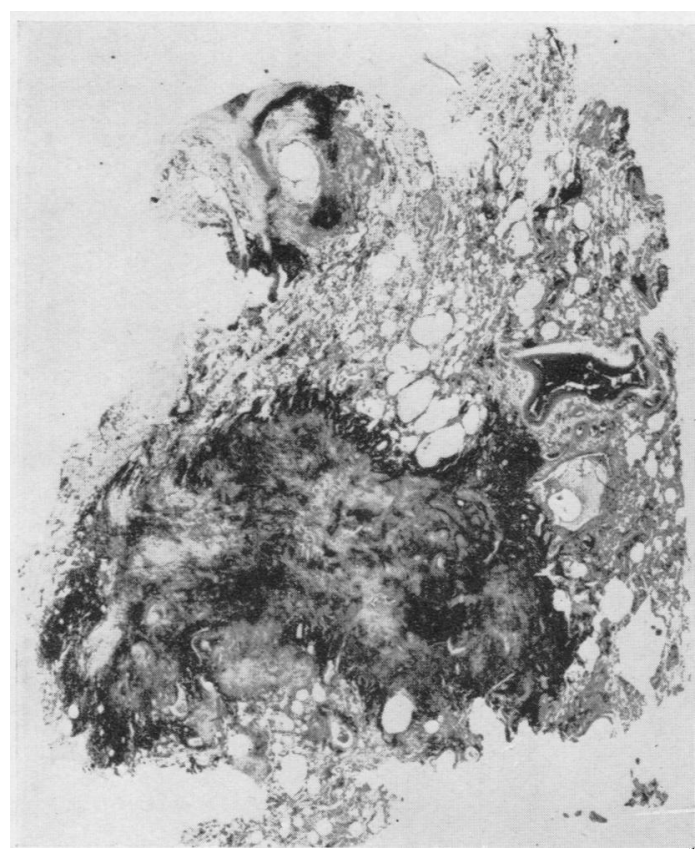

FIG. 1.-Case 1: tuberculo-silicotic nodule with focal emphysema. Haematoxylin and eosin. $\times 4$.

Case 2.-H. R. was 54 years old when he died in November, 1948. At the age of 13 years he went to work in the office of a firm of brass founders, and after a short time became a brass moulder. He continued at this job for about 15 years, when he was out of work

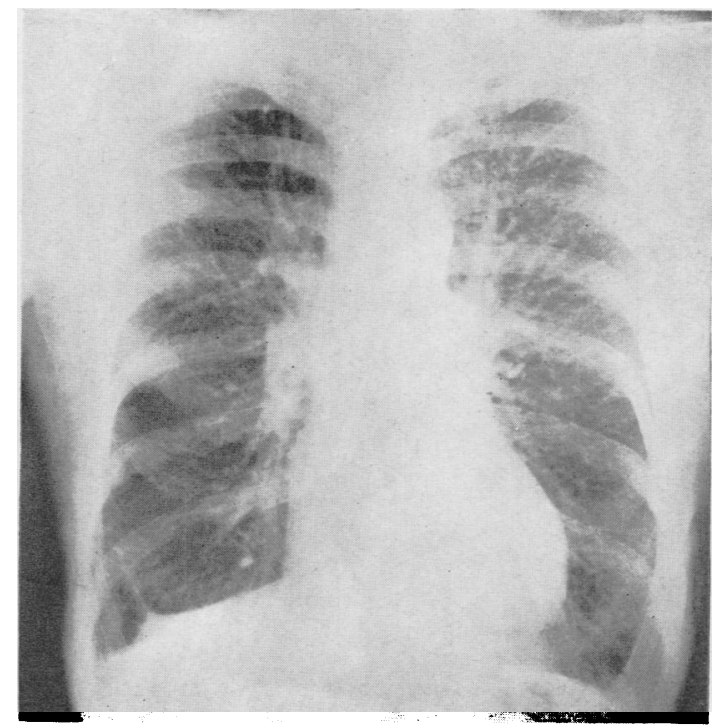

FIG. 2.-Case 2 : $x$-ray film of the chest (1946) showing generalized increased linear striation with some reticulation.

for a period. He returned to his job as a brass moulder and continued as such until six years before his death when he became " ill with his chest " and was in hospital for six months. He then returned to his work for a few months, but had not worked thereafter. He was engaged in brassmoulding for about 32 years. The parting powder used during the first period of his working life was sieved burnt sand, and during the second a proprietary non-siliceous preparation.

Little information is available about his illness. He is known to have attended a chest clinic and no evidence of tuberculosis was found. Two $x$-ray films of the chest are available, one taken in May, 1942, and the other in December, 1946 (Fig. 2). The first film showed increased linear striation with some fairly large opacities at both bases. There were more abnormal shadows, especially at the bases, in 1942 than there were in 1946. It is likely that in 1942 he was suffering from a form of subacute pulmonary congestion which had cleared by 1946 . The second film (Fig. 2) shows generalized increased linear striation with some reticulation, but no nodulation. There is "peaking" of the right diaphragm, suggesting the presence of adhesions. This was seen also in the earlier film.

At necropsy the body was very wasted, and all the organs were wasted except the thyroid, which was moderately enlarged: the heart, which weighed $12 \mathrm{oz}$., showed dilatation with some hypertrophy of both ventricles. The lungs showed marked emphysema with much pigmentation, some small palpable black nodules, and acute bronchitis.

Microscopically the lungs showed both a generalized and some focal emphysema with small but definite areas of pneumoconiotic fibrosis (Fig. 3). A hilar lymph node showed linear fibrosis amongst pigment. 


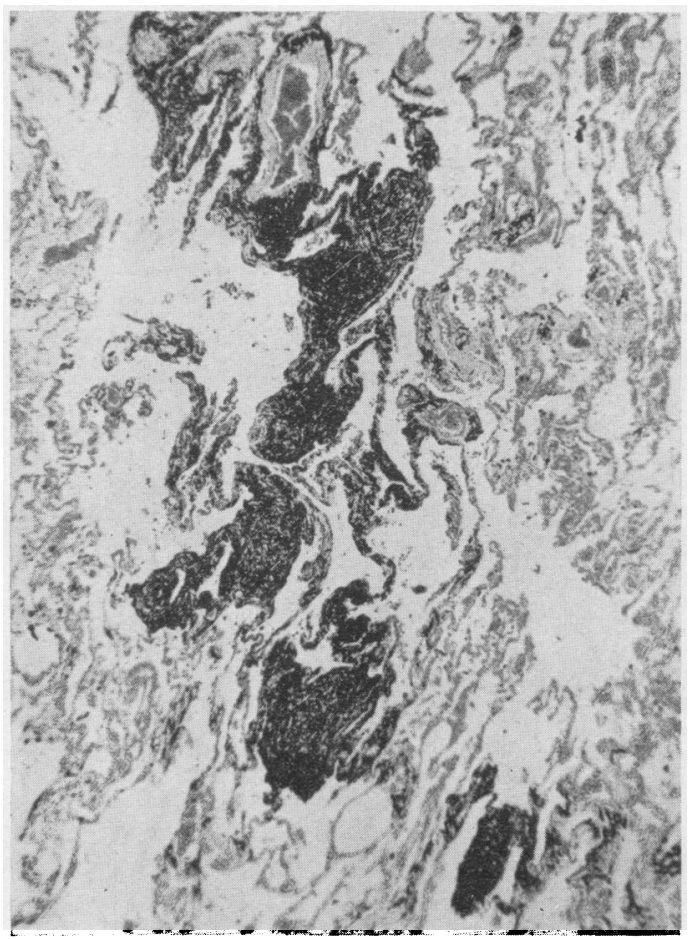

FIG. 3.-Case 2: early mixed-dust fibrosis and focal emphysema. Haematoxylin and eosin. $\times 30$

Case 3.-P. T. was aged 56 years when he died in January, 1950. He had been a caster of copper pipes for 31 years at one works and previously for a few years had been an under-hand at a brass foundry. Before this he had worked on the railway for a few years after leaving school. His main work had consisted in pouring molten copper into " cannon type" iron moulds, which were lined with a mixture of plumbago and oil, and without any added siliceous material. Plumbago, or natural graphite, usually contains a small percentage of free silica. The moulds were water-cooled before the castings were removed. Apart from frequent attacks of metal fume fever he was said to have enjoyed good health until 1945 when he was forced to give up his work because of dyspnoea. In June, 1949, he was admitted to hospital for six weeks. He gave a history of gradually increasing breathlessness on exertion, cough, loss of weight, and joint pains over the previous four or five years; swelling of the legs for two months, and cyanosis for two weeks.

On examination he was thin, wasted, and orthopnoeic. The heart was enlarged and there were signs of emphysema and congestion at the bases of both lungs. There was gross oedema of the legs. Blood pressure was $160 / 110 \mathrm{~mm}$. $\mathrm{Hg}$.

An $x$-ray examination on June 13, 1949 (the film is not available), showed that "the cardiac outline appears a little larger than usual and there is well- marked calcification in the arch of the aorta. The lung fields show a generalized increase in the markings with obliteration of the right costophrenic sulcus. This picture could well fit in with the previous occupational history. There is no evidence of active tuberculosis". A blood count was within normal limits ; an electrocardiograph tracing showed right axis deviation. The signs of cardiac failure cleared up during treatment in hospital and he went home where he died six months later.

The fixed specimens showed old pleural adhesions, especially at the bases of the lungs : the pleura elsewhere was black with fairly noticeable white lymphatic markings. The lungs showed much black pigment, had marked emphysema both focal and general, but contained no palpable nodules. There was acute bronchitis more marked in the upper parts of the lungs. The hilar lymph nodes were large, very black, and moderately firm. No tuberculosis was visible.

Microscopically there was diffuse thickening of the alveolar walls in the lungs, largely cellular but with some collagen and with fairly numerous foreign body giant cells which were not particularly associated with pigment. There were some small areas of mixed-dust fibrosis. The hilar lymph nodes were markedly congested; they contained a fair amount of pigment but showed little fibrosis.

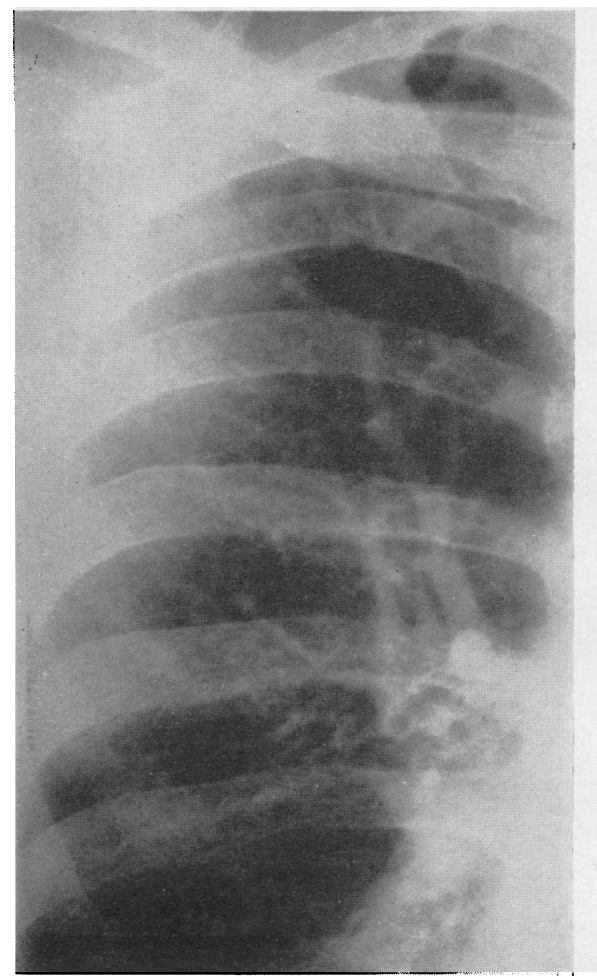

FIG. 4.-Case 4: $x$-ray film of chest showing generalized increased linear striation with a background of reticulation in right upper zone. 
Case 4.-J. J. G. was 50 years old when he died on December 20, 1952. He left school at 14 years of age and was a brass moulder nearly all his working life, with the exception of three years between 1936 and 1939 when he worked at the docks as a ship's plumber. At his last factory, where he had worked for 12 years, he had done nine years "floor" moulding and three years core making. Altogether he had been a brass moulder for nearly 40 years. No information about the parting powders used in the foundries is available.

About two years before his death he began to get short of breath and he consulted his doctor who sent him for $x$-ray examination. It was reported that the chest film showed the presence of pneumoconiosis (Fig. 4). The picture is one of increased linear striation with a background of reticulation. He refused to apply for compensation, and he went back to work and continued with increasing difficulty owing to dyspnoea until October 11, 1952, when he could no longer work. He died at home two months later.

The fixed lungs showed marked apical and marginal emphysema ; in addition there was focal emphysema around small pigmented areas which were doubtfully palpable. The bases were congested and partly autolysed. The hilar lymph nodes were soft and not very pigmented.

Microscopically the lungs showed acute bronchopneumonia. There was slight pneumoconiosis with slight focal emphysema. The sections showed comparatively little pigment, of which a little was iron and only a very little silica.

Case 5.-G. E. G. was 76 when he died in January, 1954. He worked as a brass fettler for 45 years, giving up work in 1952. In early life he spent eight years in various jobs that did not carry a risk of pneumoconiosis. His health had been good until the end of 1951 when he noticed that he was short of breath on effort, and he developed an intermittent cough. In 1952 he was found to have a blood pressure of $220 / 100 \mathrm{~mm}$. $\mathrm{Hg}$ and an enlarged heart with a systolic murmur. An $x$-ray examination (Fig. 5) in May, 1953, showed that there was coarse nodulation in both lungs while below the right clavicle there was massive fibrosis. His death was reported as due to coronary occlusion from coronary atherosclerosis with silicosis of the lungs as an accessory factor.

The lungs after fixation showed a dense, white (" sugar icing ") thickening of the pleura in irregular patches at the apices and elsewhere, the largest patch being 1 in. in diameter : in addition there were many small, white, palpable dots on the blue-black pleura. In the right lung was a mass of conglomerate nodules below the apex about 2 in. in diameter and showing a little ischaemic necrosis at the centre; hard, rounded, black nodules about $\frac{1}{4}$ in. in diameter, forming occasional small agglomerates, were scattered throughout the lung lessening in number towards the base. Focal emphysema was not a conspicuous feature but there was fairly notable emphysema at the base of the lung. The left lung was similar to the right but not so badly affected. No evidence of tuberculosis was seen in either lung. The

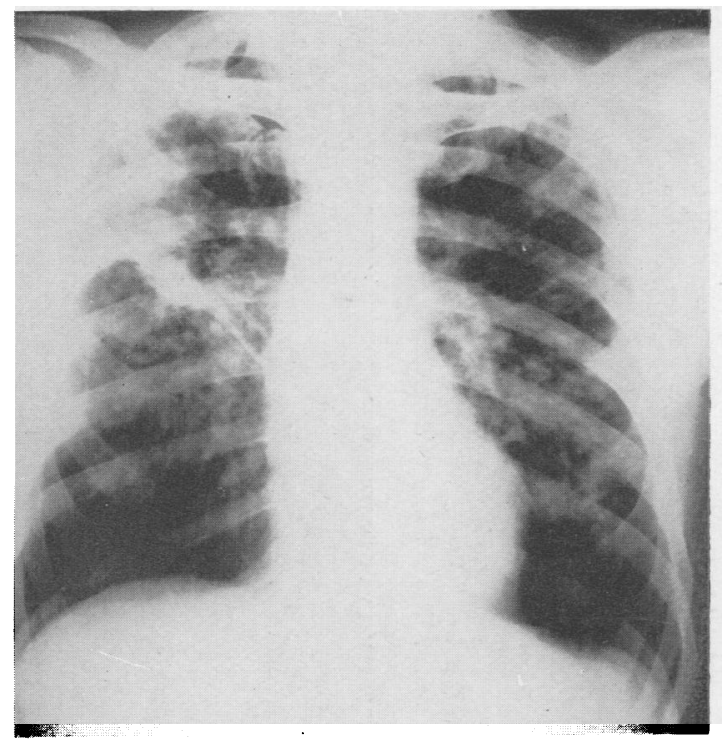

FIG. 5.-Case 5: $x$-ray film of chest showing nodulation in upper two-thirds of both lungs, with a massive shadow in the right upper lobe, and translucent areas at both bases suggesting the presence of bullous emphysema.

hilar lymph nodes were moderately enlarged, black, and very firm.

A large section of the left lung (Fig. 6) shows nodular silicosis and also some stellate nodules of simple pneumoconiosis with focal emphysema. Microscopically (Figs. $7,8)$ the lungs show whorled silicotic nodules tending to aggregate and also linear dust fibrosis.

Case 6. -N. T. was aged 56 years when he died in 1954. On leaving school he was apprenticed to a brush maker for three years. He was an iron fettler for nearly three years, he did a year's military service, and then had two more years as an iron fettler. He was then unemployed for 15 months, and afterwards worked as a domestic gardener for nearly six years. From June 22, 1928, until July 14, 1952, i.e., for 24 years, he worked as a bronze fettler for a firm in the Sheffield area. He gave up work two years before his death on account of a chest illness. An $x$-ray film (Fig. 9) taken in June, 1952, shows coarse reticulation with some nodulation in the upper two-thirds of both lungs. A well-marked "honeycomb" appearance is seen in the mid-zones, there is increased translucency over the lower thirds of both lung fields, and irregularity of both diaphragms, suggesting emphysema and diaphragmatic adhesions.

The bronze foundry in which he worked for 24 years is housed in a bay of a large building which also contains a steel foundry. The ventilation arrangements for the removal of melting and casting fume are now excellent but have probably not always been so. The moulds for casting are made partly of cement and partly of sand. Little visible burnt-on sand remains on the castings after they have been knocked out of the mould. Fettling is done mainly by pneumatic chisels, but also by portable grinders. Exhaust ventilation is not applied to these 
Fig. 6.-Case 5 : section of left lung showing well-marked silicotic nodulation with some stellate nodules of mixed-dust fibrosis. Approximately half natural size.

Fig. 7.-Case 5 : agglomerate silicotic nodule. Haematoxylin and eosin. $\times 10$

Fig. 8.-Case 5 : mixed-dust fibrosis (simple pneumoconiosis) and focal emphysema. Haematoxylin and eosin. $\times 24$.

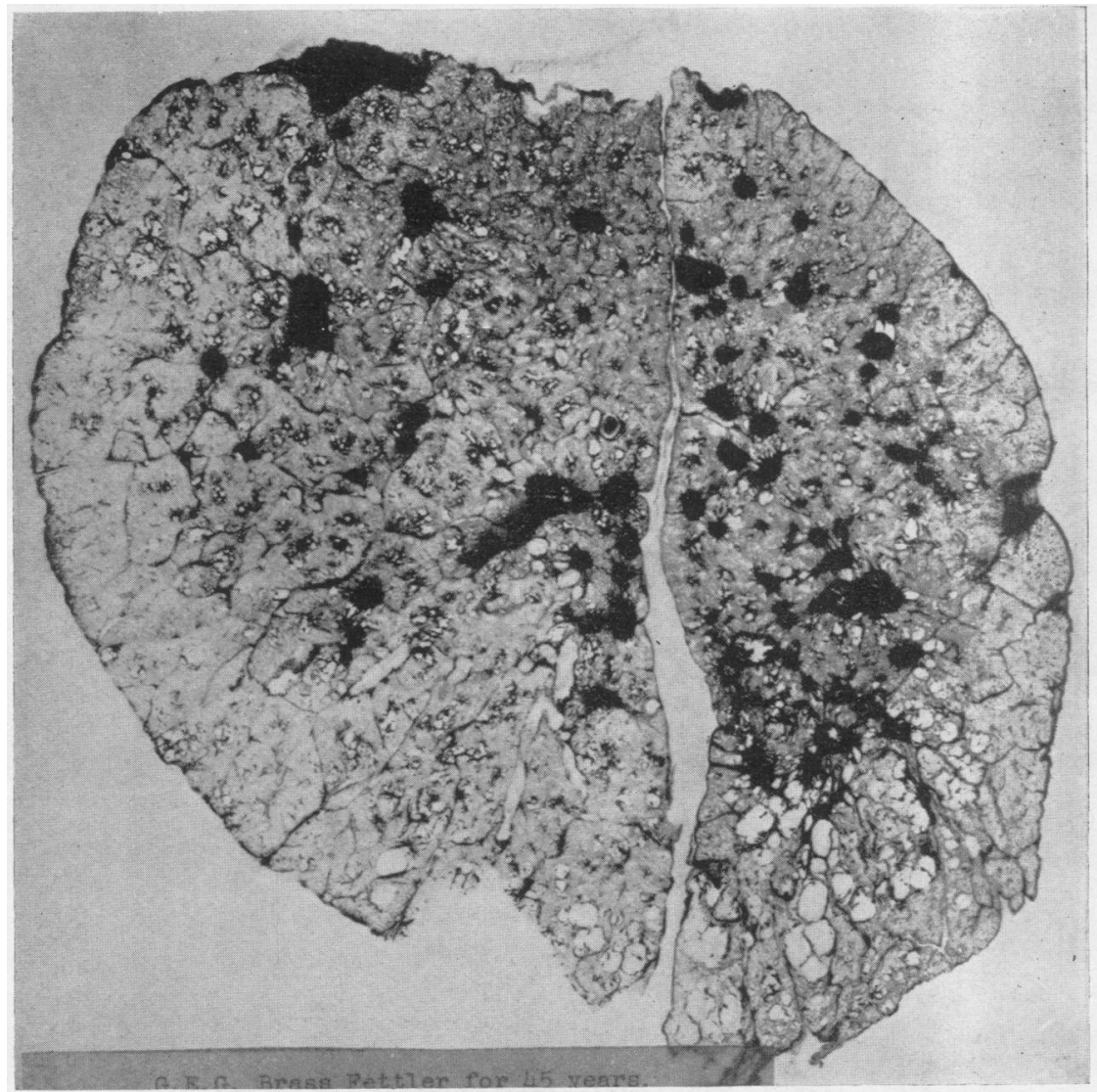

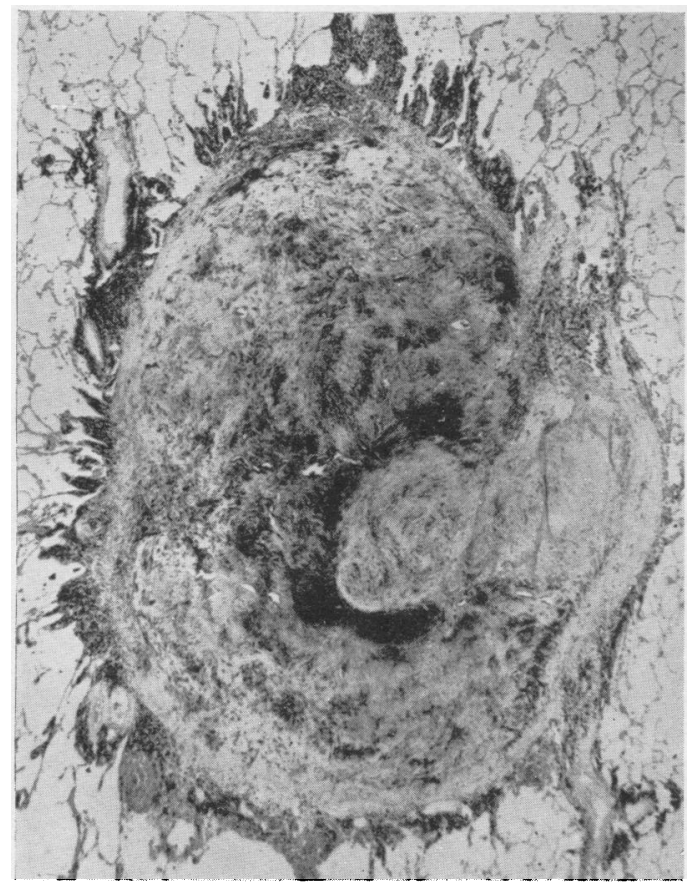

FIG. 7

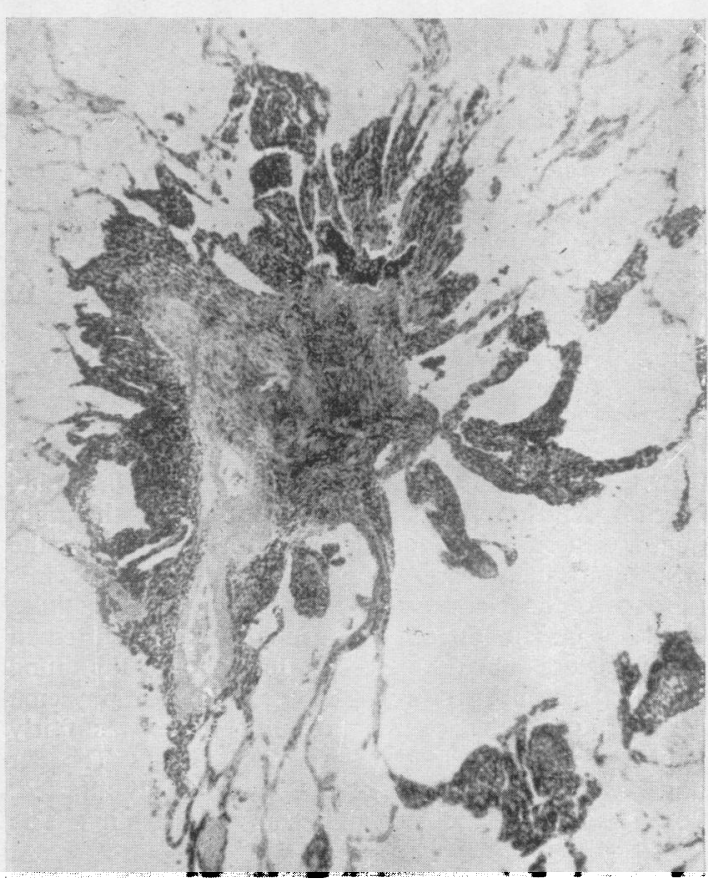

FIG. 8 


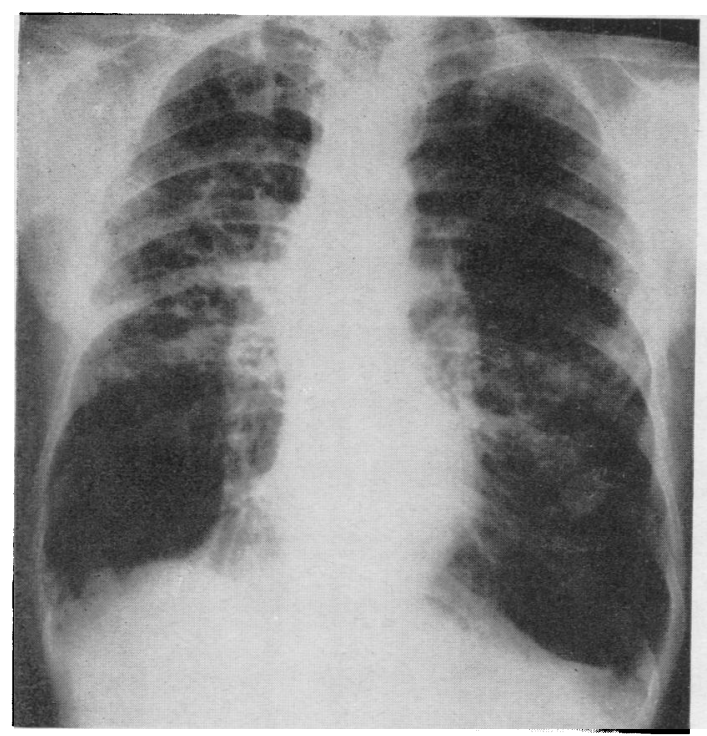

Fig. 9.-Case 6: $x$-ray film of chest showing " honeycombing" with some nodulation and reticulation in upper two-thirds of lungs.

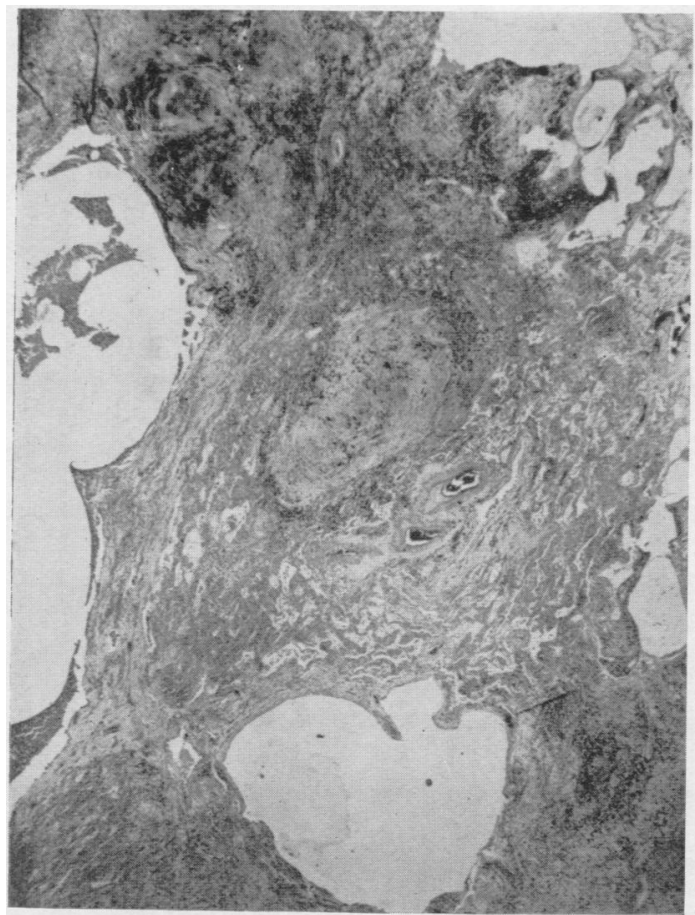

FIG. 10.-Case 6: Bronchiectatic cavities surrounded by fibrosis together with silicotic nodulation and focal emphysema. Haematoxylin and eosin. $\times 13$. tools. Fettling is also done by large abrasive wheels to which exhaust ventilation is applied.

After a post-mortem examination, Dr. D. Guest reported that death was due to "toxaemia and heart failure from bronchopneumonia, associated with silicosis of the lung and chronic purulent bronchitis".

To the naked eye the fixed lungs showed many pleural adhesions, widespread bronchiectasis with bronchopneumonia, and several abscesses : some small fibrous nodules were palpable in each lung apparently distinct from the fibrosis due to bronchiectasis.

Microscopically (Fig. 10) the lungs showed bronchiectasis, bronchopneumonia with abscess formation, some whorled fibrous nodules, and slight simple pneumoconiosis with focal emphysema.

\section{Chemical Analysis of Lungs}

The results of chemical analysis are given in the Table and are expressed as percentages of dried weight of lung. They are not necessarily comparable with those of other authors. All the lungs had been in fixative (formol-saline), often for long periods, and had been cut into in many places before samples were taken for analysis. An attempt was made in each case to get a representative sample of the whole of both lungs : no chemical analyses were made of fibrous areas alone. It may be noted that there was a rough correlation between the percentages of free silica and the amount of fibrosis (both whorled and linear) found in the lungs. The free silica estimations were made by the method of Trostel and Wynne (1940); the other estimations by standard chemical methods. No appreciable quantity of zinc or copper was present in the ash of the lungs.

TABLE

RESULTS OF CHEMICAL ANALYSIS OF LUNGS

\begin{tabular}{c|c|c|c|c}
\hline Case & Ash & Total Silica & Free Silica & Iron (as $\mathrm{Fe}_{2} \mathrm{O}_{\mathbf{3}}$ ) \\
\hline 1 & 4.45 & 1.39 & 0.55 & 0.59 \\
2 & 3.34 & 0.35 & 0.11 & 0.49 \\
3 & 4.51 & 0.16 & 0.02 & 1.3 \\
4 & 1.45 & 0.10 & 0.06 & 0.33 \\
5 & 5.11 & 1.2 & 0.60 & 1.21 \\
6 & 4.15 & 0.82 & 0.58 & 1.51 \\
\hline
\end{tabular}

$X$-ray analysis of the ash of Case 5 showed 7\% of quartz (i.e., $0 \cdot 36 \%$ of dried lung), while analysis of a nodule from the lung showed $1.5 \%$ of the dry weight to be quartz.

\section{Discussion}

The conclusions which can be drawn from the study of this small series of cases can only be tentative, but it seems reasonable to assume that many of the pathological changes found can be related to the occupation. Brass and bronze moulders and casters who work with sand moulds are exposed to the inhalation of dusts and fumes 
which may vary quantitatively and qualitatively with the conditions of ventilation and the technique of moulding and casting in the individual shop. The sand used has usually a lower free silica content (about $80 \%$ ) than that used for steel castings (about $95 \%$ ), because the melting temperatures of these non-ferrous metals are lower than that of steel and iron. The melting temperatures are also relevant in the cases of fettlers, because they largely determine whether or not burnt-on sand will be left on the castings. It is the dust created by vigorous methods for removing the sand from the castings which causes silicosis and mixed-dust fibrosis.

Moulders and casters are also exposed to the inhalation of dusts caused by the application of parting powders and mould dressings. The Foundries (Parting Materials) Regulations came into force in 1950 and they prohibit the use of parting powders containing more than $3 \%$ of compounds of silicon. Before that date siliceous parting powders were freely used, though many parting powders used before 1950 were silica-free. Many proprietary parting powders are on the market, and contain such substances as zirconium silicate, calcium carbonate, calcined china clay, sillimanite, fused alumina, and olivine.

These workers are also invariably exposed to the inhalation of freshly formed zinc oxide and to a lesser extent to the oxides of other metals such as copper, tin, and lead. Some, but not all, brasses contain lead, but none of the cases described in this paper had suffered from lead poisoning.

Of the four moulders and casters, the immediate cause of death in two was bronchopneumonia (one tuberculous) and in the other two cor pulmonale or right-heart failure. All four had marked emphysema, both general and focal, associated with bronchitis. It may well be that emphysema and bronchitis arise partly or mainly from the inhaled dusts and fumes, though it is difficult to produce convincing evidence. But an agent which irritates the pulmonary tissue is also likely to irritate the bronchial mucous membranes.

The amount of occupational fibrosis found in the lungs of the moulders varied. In one case there was well-marked silicosis (associated with tuberculosis); in two others there were definite though not severe areas of mixed-dust fibrosis (which we regard as modified silicosis), and in the fourth there was only slight mixed-dust fibrosis. The man who had the shortest exposure to brass moulding and casting (29 years) had the most marked fibrosis, but he was known to have used a siliceous parting powder for some years. The other three patients had been employed for 32,31 , and 40 years respectively. It is not known for certain if they had used siliceous parting powders, but inquiries suggest that if they had, large quantities were not used. These three men, however, would be exposed to dry siliceous dust arising from the process of knocking away the sand moulds and cores after casting. Such dust might well account for the mixed-dust fibrosis or modified silicosis found in their lungs.

The two brass fettlers or dressers both had silicotic nodules in the lungs. One (Case 5), who had been doing the work for 43 years, developed moderately marked silicosis with some mixeddust fibrosis and focal emphysema. There was also some gross emphysema at the bases of the lungs. The immediate cause of death was coronary thrombosis. The other (Case 6) had worked for 24 years as a bronze fettler and five years as an iron fettler. Death was mainly caused by bronchopneumonia associated with bronchiectasis and abscess formation : however, some fibrous nodules, both of the silicotic and mixed-dust fibrosis types, were present in the lungs.

Though there is not a great deal of visible burnt-on sand on brass castings there is enough to cause some pulmonary fibrosis amongst the fettlers. Our general impression from these cases and our previous studies of iron fettlers (Harding, Gloyne, and McLaughlin, 1950) is that the lungs of iron fettlers become damaged more quickly than those of brass fettlers. This is consistent with the fact that the melting temperature of iron is higher than that of brass and therefore more burnt-on sand is found on iron castings.

The pathological features of these lungs are similar to those found in workers in iron and steel foundries (Harding and others, 1950). Simple pneumoconiosis or mixed-dust fibrosis accompanied by focal emphysema as in colliers' lungs is the commonest finding. True whorled silicotic nodules are also occasionally found, as well as transitions between the stellate nodules with linear or radial fibrosis and the classical nodules with whorled dense fibrosis. Both types of lesion are seen in the lungs of Case 5, and possibly represent differences in the silica content of the dust at different periods. As with pneumoconiosis in other trades, tuberculosis and other infections seriously complicate the picture.

\section{Summary}

Clinical, radiographic, environmental, and pathological (gross, histological, and chemical) details of six non-ferrous foundry workers (four moulders and casters, and two fettlers) are described. 
All six cases showed varying degrees of occupational pulmonary fibrosis, either whorled silicotic nodulation, linear or stellate fibrosis (mixed-dust fibrosis), or transitional stages between these two types of fibrosis.

Though all cases showed fibrosis, it was a clear factor in the deaths of only two of them (Cases 1 and 5); it was doubtfully so in two others (Cases 2 and 6) and was insignificant in the remaining two (Cases 3 and 4).

The pathological features of the lungs of nonferrous foundry workers are similar to those found in iron and steel foundry workers. Both moulders and fettlers are liable to contract silicosis and mixeddust fibrosis which may be complicated by pneumonia, tuberculosis, and chronic bronchitis and emphysema with right-heart failure.

We are indebted for much help in collecting information about these six cases to the following: Dr. P. K. Walker, Dr. S. Bryson, and Dr. H. Blyth, of the Pneumoconiosis Panels, Ministry of Pensions and National Insurance ; Dr. W. D. Buchanan, H.M. Medical Inspector of Factories, Ministry of Labour and National Service ; the Records Officer, Leeds General Infirmary, for clinical details of Case 3 ; Dr. H. Midgley Turner, Chief Chest Physician, Sheffield, for clinical and radio- graphic details of Cases 1 and 2 ; Dr. R. Hardy, Chief Chest Physician, Hull, for the $x$-ray film of Case 4 ; and to Dr. Denton Guest, Huddersfield, and Dr. A. P. Massie, Hull, for additional pathological details about Cases 4 and 6 respectively. Part of the expenses of this investigation was met by a grant to one of us from the Research Fund of the University of Sheffield. The photomicrographs were made by Mr. A. W. Collins, F.I.M.L.T.

\section{REFERENCES}

Brown, E. W., and Klein, W. E. (1942). U.S. Naval Med. Bull., $40,42$.

Greenburg, L., Siegel, W., and Smith, A. Ross (1938). Spec. Bull. No. 197, New York State, Department of Labor.

Hamlin, L. E., and Weber, H. J. (1947). J. Industr. Hyg. Toxicol., 29, 367 .

Harding, H. E., Gloyne, S. R., and McLaughlin, A. I. G. (1950). Chap. $V$ in McLaughlin and others "Industrial Lung Diseases of Iron and Steel Foundry Workers," p. 90. H.M.S.O., London.

McLaughlin, A. I. G., Cheeseman, E. A., Garrad, J., Gloyne, S. R., Goodall, K. L., Harding, H. E., Jupe, M. H., Lawrie, W. B., Perry, K. M. A., Sutherland, C. L., and Woods, H. (1950).
"Industrial Lung Diseases of Iron and Steel Foundry
Workers."

Riley, E. M., Butler, R. W., and Goren, S. (1945). U.S. Naval Med. Bull., 44, 653.

Sander, O. A. (1939). Fourth Saranac Symposium on Silicosis, Saranac Lake, N.Y.

Stalker, W. W. (1947). J. Industr. Hyg. Toxicol., 29, 96.

Trice, M. F., and Easom, H. F. (1936). Report of a Study of the Foundry Industry in North Carolina. North Carolina State Board of Health and Industrial Commission Division of Industrial Hygiene.

Trostel, L. J., and Wynne, D. J. (1940). J. Amer. Ceramic Soc., $23,18$.

Vigliani, E.C., Parmeggiani, L., and Zanetti, E. (1948). Med. Lavoro, 